\title{
INSTITUIÇÕES PARTICIPATIVAS SOB A ÉGIDE DO LULISMO'1
}

\author{
Wagner Romão* \\ Françoise Montambeault** \\ Frédéric Louault ** *
}

\begin{abstract}
A tese do lulismo (Singer, 2012) se baseia no argumento da alteração da composição das bases eleitorais dos ex-presidentes brasileiros Luis Inácio Lula da Silva (Lula) e Dilma Rousseff (Dilma), da classe média razoávelmente ilustrada para eleitores com renda média de até dois salários mínimos. No entanto, é mais do que isso: a referida tese propõe que o lulismo atualiza a conciliação entre a melhoria das condições de vida dos mais pobres, sem prejudicar os setores conservadores. "Reformismo fraco" é o termo proposto por Singer. Nossa proposta consiste em analisar as ações do período Lula-Dilma sob esse enfoque teórico. Elemento fundamental do projeto político petista de democracia participativa para o Brasil, as instituições participativas (IPs) proporcionaram mobilização de atores sociopolíticos de sua base mais tradicional de apoio. No entanto, de maneira coerente com os marcos do lulismo, as IPs mantiveram padrões de efetividade política fraca e de carência de legitimidade face às instituições da democracia representativa.
\end{abstract}

PALAVRAS-CHAVE: Instituições participativas, Lulismo, Petismo, Movimentos sociais, Governo

\section{INTRODUÇÃO}

O período de cerca de 15 anos de governos da esquerda na América Latina, em geral, e no Brasil, em particular, trouxe expectativas múltiplas de políticas públicas de inclusão social, de redistribuição e de redução das desigualdades entre observadores, militantes e intelectuais da região. A possibilidade da construção de regimes de cidadania mais in-

\footnotetext{
* Instituto de Filosofia e Ciências Humanas - Universidade Estadual de Campinas - Unicamp. Rua Cora Coralina, 100, Cidade Universitária Zeferino Vaz, Barão Geraldo, CEP13083-896, Campinas - São Paulo - Brasil -..wromao@ unicamp.br

http://orcid.org/0000-0003-3725-2861

* * Université de Montréal - Départament de science politique, 3150, rue Jean-Brillant, Pavillon Lionel Groulx, CP 6128, succ. Centre-ville, Montréal, Québec H3C 3J7, Canadá - francoise.montambeault@umontreal.ca http://orcid.org/0000-0002-5548-9291

$* * *$ Université Libre de Bruxelles - Départamento de ciência política - Faculdade de Filosofia e Ciências Sociais, Avenue F. D. Roosevelt 50, CP 124 (CEVIPOL), 1050 Bruxelles, Belgium. flouault@ulb.ac.be http://orcid.org/0000-0002-7330-078X

1 Os autores agradecem o apoio recebido pela parceria G3-Fapesp no projeto de cooperação internacional Participatory democracy and citizenship trajectories: citizens, militants and bureaucrats. Também agradecem as sugestões apresentadas pelos pareceristas anônimos.
}

clusivos e de sistemas políticos participativos voltados para romper com a história de exclusão social e de desigualdades passou a ser possível, baseada em grande parte no discurso crítico desenvolvido pela chamada 'nova esquerda' e os seus atores principais (Montambeault, Balán \& Oxhorn, 2019).

No Brasil, a ideia de uma refundação do sistema político pelos caminhos da democracia participativa foi associada à emergência política do Partido dos Trabalhadores (PT) nas décadas de 1980 e 1990 (Keck, 1991; Sanchez, 2002; Secco, 2011). De fato, a crítica da democracia representativa como reprodutora das desigualdades históricas e dos privilégios das classes altas e conservadoras era central na construção da proposta participativa e do discurso sobre a inversão de prioridades do PT na sua gênese. Em retrospectiva, pode-se argumentar que a esquerda brasileira iniciou e intensificou processos participativos e contribuiu com o desenvolvimento da arquitetura participativa institucional no Brasil desde o nível local até o nível nacional ao longo dos anos, tendo o PT como ator político principal da sua articulação (Tranjan, 2016) 
No entanto, também é verdade que as estruturas de participação institucional - especialmente os conselhos de políticas públicas em nível local, estadual e nacional - se constituíram por iniciativas que vão além das esquerdas partidárias e do PT. Em parte, foram constituídos por movimentos sociais e grupos de interesse que pressionaram os poderes públicos a estabelecer espaços institucionais (previstos em legislação) para a negociação de suas demandas. De outra parte, os próprios governos nos três níveis da federação compreenderam a necessidade de imprimir alguma racionalidade e organização às demandas a eles apresentadas pela sociedade civil, em diversos setores de políticas públicas.

Assim, no desenvolvimento da democracia participativa no Brasil após a Constituição de 1988, operou, por um lado, um elemento mais relacionado à evolução institucional de setores mais tradicionais das políticas públicas (saúde, educação, assistência social, direitos da criança e do adolescente), fortalecidos pela redemocratização do país e, por outro lado, a força da marca democrática e popular dos governos de esquerda liderados pelo Partido dos Trabalhadores - PT.

A chegada do PT ao governo federal em 2003 aproximou estes dois eixos paralelos. A arquitetura participativa no Brasil se fortaleceu em determinados setores de políticas mais institucionalizados e também, na prática, criou novos setores que nasceram simultaneamente aos seus próprios aparatos participativos. No entanto, não foram satisfeitas as altas expectativas geradas, especialmente, pelo estabelecimento de um sistema nacional de participação cidadã integrado e coeso que nunca foram plenamente satisfeitas (Teixeira, 2014; Montambeault, 2018).

Como explicar este resultado? Por que a arquitetura participativa se configurou com estas características sob os dois períodos de presidência petista (Lula e Dilma)? Como a ameaça do legado das gestões federais de Lula e de Dilma e da construção participativa desde a Constituição de 1988, pelo atual governo federal, pode nos ajudar a compreender o que se passou entre 2003 e 2016?

Neste artigo, propomo-nos refletir sobre essa questão sob o marco teórico do lulismo, conceito imaginado primeiramente por Singer (2009) para entender o comportamento eleitoral dos brasileiros nas duas primeiras gestões petistas, e depois, reinterpretado como ferramenta analítica para entender a evolução das relações e interações entre o Estado e a sociedade naquele período. Através dessa aproximação teórica, pretendemos fornecer ferramentas para entender melhor a construção das interfaces sócio-estatais e o legado participativo daquela gestão, bem como os seus limites inerentes. Além disso, o modo como se deu o funcionamento das instituições participativas nos governos petistas (Lula, 2003-2010 e Dilma, 2011-2016) nos ajuda a compreender os sentidos do lulismo como categoria de análise enquanto regime político de articulação de interesses contraditórios. Mostramos que essas contradições inerentes ao lulismo contribuem para explicar tanto a capacidade de mobilização das instituições participativas no Brasil (especialmente através da influência de atores sociopolíticos tradicionalmente associados ao PT), quanto as limites daquelas IPs em termos de efetividade política e de legitimidade frente as instituições da democracia representativa. O presente artigo também reflete sobre a crise do lulismo após a perda de popularidade de Dilma Rousseff em junho de 2013 e a polarização política no Brasil, visível desde as grandes manifestações de rua até o contexto das eleições de 2018 e do governo Bolsonaro.

O trabalho está organizado da seguinte forma: em primeiro lugar iremos apresentar o lulismo como conceito, a partir da caracterização de André Singer (2009) e da apropriação do conceito por certa literatura para expressar o pacto de governabilidade intrínseco ao lulismo. Em seguida, indicaremos como a literatura tem lidado com o conceito de lulismo contraposto à ideia de petismo, de modo a traduzir as 
diferenças entre a ação do PT e de Lula, antes e depois de 2003, sobretudo, na relação entre os governos e os movimentos sociais e a participação institucional. Explicitaremos também nossas divergências desta visão. Em terceiro lugar, analisaremos como as chamadas instituições participativas serviram aos princípios do lulismo. Por um lado, criaram-se espaços de ampla mobilização dos movimentos sociais da tradicional base de apoio ao petismo. Por outro lado, os limites das instituições participativas como espaços de efetivo poder explicitam também os limites institucionais e políticos do lulismo para o aprofundamento da democracia no Brasil, a partir da iniciativa do governo federal. Por fim, indicaremos como a radicalização política em meio ao primeiro governo Dilma após junho de 2013 - e o consequente rompimento do lulismo - coincide com a reação conservadora à Política Nacional de Participação Social, na mais firme tentativa de dar força política às instituições participativas em nível federal.

\section{O CONCEITO DE LULISMO}

Nascido a partir de uma hipótese sobre o realinhamento eleitoral de determinados estratos sociais, observado na eleição presidencial de 2006 no Brasil, o conceito de lulismo abarca um fenômeno político mais complexo e amplo. A partir dele, avançou-se para além de análises de comportamento eleitoral para o estudo da evolução do PT como partido político (o lulismo como base de identificação partidária diferente do petismo) ${ }^{2}$, das relações entre a esquerda e os setores conservadores, a atuação das classes sociais na política, o papel dos movimentos sociais nos governos petistas, entre

2 Destaca-se que se a tese do lulismo foi muito influente na literatura sobre comportamento eleitoral no Brasil, há um debate importante na literatura sobre o conceito desenvolvido pelo Singer, com autores criticando a explicação do lulismo como base para entender a construção da base partidária do PT (Samuels, 2004), a reeleição do PT em 2006 (Zucco 2008) e dos governos de Dilma (Bezerra, 2019). outros temas da economia e ciência política. O conceito serve também para a compreensão das relações entre a estrutura social e o modelo de desenvolvimento social e econômico durante as gestões de Luis Inácio Lula da Silva (2003-2010) e Dilma Rousseff (2011-2016).

A tese de Singer (2009) supõe que se o PT foi construído com apoio dos movimentos sociais, das camadas médias e dos intelectuais e de que a chegada de Lula ao poder no nível federal foi acompanhada da emergência do que o autor chama de uma nova 'matriz' socioeconômica - o lulismo. Ele possibilita a tradução política das aspirações das classes de baixa renda sem ameaçar o modelo de desenvolvimento econômico neoliberal e a ordem social favorável aos setores conservadores da população (Amaral; Power, 2016). Porém, na tradução eleitoral desse fenômeno, o lulismo possui dois vetores conflitantes e, por vezes, contraditórios. De um lado, cria-se um realinhamento eleitoral que pode explicar a sustentação e resiliência política do governo Lula e que também se desenvolveu no governo Dilma. De fato, no final do seu primeiro mandato, Lula tinha perdido o apoio de suas bases políticas junto às camadas médias do eleitorado, a qual passou a reprová-lo majoritariamente em meados de 2005. Não estão totalmente claros os motivos pelos quais isso ocorreu. Elencam-se fatores como a reforma da Previdência do setor público, ocorrida ainda em 2003, e principalmente, a rejeição a partir da crise do "mensalão" ${ }^{3}$ que derrubou ministros do entorno político do presidente. Este eleitorado - importante recurso à eleição de Lula em 2002 e em suas disputas eleitorais anteriores - passara a rejeitá-lo.

Enquanto isso, no sentido contrário, "houve um movimento subterrâneo de eleitores não de baixa renda, mas de baixíssima renda, que tendem a ficar invisíveis para os analistas" (Singer, 2012, p. 53). Também aqui não é possível identificar concretamente as causas do fenômeno, mas há pouca dúvida de que um

3 Escândalo politico-midiático que envolveu o PT e outros partidos politicos em 2005. 
conjunto de políticas públicas como o Programa Bolsa Família, o Luz para Todos, o aumento real do Salário Mínimo e até mesmo uma forte identificação desta parcela do eleitorado com a trajetória de Lula podem ter contribuído para essa mudança, provocando uma alteração nas bases materiais do voto (Singer, 2012, p. 63). Singer utiliza o termo lulismo inicialmente para caracterizar esse realinhamento eleitoral de mão dupla, com o progressivo abandono das camadas médias do voto em Lula - estes eleitores potenciais do PT até 2002 - e a conexão eleitoral mais direta de Lula com os eleitores de renda familiar de até cinco salários mínimos, até então votantes nas candidaturas mais conservadoras. ${ }^{4}$

Porém, o elemento fundamental que conecta o fenômeno eleitoral com uma interpretação mais profunda da realidade política brasileira é a ideia de mudança sem confronto com o capital, que caracteriza o lulismo como um fenômeno de conciliação de classes. Singer recupera trabalho anterior (Singer, 2000) e defende a tese de que a rejeição a Lula se dava entre os mais pobres por certa hostilidade deste público com relação às greves (sendo Lula identificado com elas) e também a uma intuitiva autolocalização à direita do espectro político. Assim, os mais pobres buscavam a redução das desigualdades por meio da ação do Estado, mas eram refratários a quaisquer movimentos que pudessem "desestabilizar a ordem". A busca dos mais pobres seria por uma figura política que fizesse as mudanças pelo alto, "uma autoridade constituída que pudesse proteger os mais pobres sem ameaça de instabilidade" (Singer, 2012, p. 58).

Deste modo, a síntese do lulismo - para além de um mero fenômeno de realinhamento eleitoral - refere-se à articulação de ações de diminuição da desigualdade e da pobreza com

4 Outros autores trataram de buscar explicações para o mesmo fenômeno. Zucco $(2008,2013)$ compreende que se trata não de uma particularidade de Lula, mas da reafirmação do fenômeno do "governismo", sobretudo no Nordeste brasileiro. Rennó e Cabello (2010), no mesmo sentido, reputam o lulismo de Singer a um voto desideologizado e reputam o lulismo de Singer a um voto desideologiza
influenciado pelo bom desempenho do governo Lula. manutenção da estabilidade política e da ordem, que comovem o eleitorado pobre e conservador. É por este veio que - sobretudo sob o signo do reformismo fraco - a literatura recente sobre o regime político brasileiro irá considerar o lulismo como um pacto interclasses sociais e um projeto político e ideológico (Nogueira, 2017). O conceito de lulismo passa a ser considerado como a referência a partir da qual se irá navegar do debate sobre o comportamento eleitoral para outros campos do conhecimento sobre o mundo político.

O conceito de lulismo nos interessa para pensar sobre o modo de governar no sistema político brasileiro e como este se coloca no lugar das expectativas investidas a partir da chegada de Lula ao governo federal. Buscaremos a seguir, comentando a literatura, precisar melhor como se configura este pacto de governabilidade, onde a tradição participativa produzida pelo PT e aliados alcança seu paroxismo.

\section{O LULISMO COMO PACTO DE GO- VERNABILIDADE}

O artigo original de Singer (2009) deu início a um conjunto de interpretações sobre o lulismo, como modelo de governo e de construção de coalizões políticas, implementado por Lula em seus mandatos no governo federal.

Mayaux (2013) desenvolve a tese do “triângulo político" do lulismo. Para o autor, a partir de 2003, Lula construiu um novo compromisso político no Brasil, por meio da conciliação entre três grandes setores da sociedade. Em primeiro lugar, o povo desorganizado, ou seja, as massas de pobres quase sempre em situação de desemprego ou emprego precário e que passaram, por um lado, a obter trabalho com o crescimento da economia, especialmente, no segundo mandato de Lula e, por outro lado, obtiveram ganhos por meio das políticas de transferência condicionada de renda pelo Programa Bolsa Família. Ainda, incorporou-se a este setor os trabalhadores registrados (com 
carteira assinada e contribuição previdenciária), que obtiveram ganhos pela política de aumento real do salário mínimo e de acesso facilitado ao crédito. Em segundo lugar, os atores financeiros e também, em terceiro lugar, o setor industrial, ao qual também agregamos o setor de agronegócio e as grandes empresas de extrativismo mineral. Os interesses financeiros e industriais aproveitaram-se de uma política econômica ortodoxa, mas que também mirou o crescimento da economia especialmente no período da crise internacional de 2008, por meio de grandes projetos em infra-estrutura articulados no Programa de Aceleração do Crescimento e do Programa Minha Casa Minha Vida, com forte apoio do Banco Nacional de Desenvolvimento Econômico e Social (BNDES).

Além desta interpretação baseada na relação dos estratos sociais e das frações da classe dominante (capital industrial / financeiro / agronegócio) com o lulismo, a literatura também aponta a prática dos pactos de governabilidade próprios do presidencialismo de coalizão nos governos de Lula e Dilma. Autores como Nobre (2013) articulam estes dois fatores. Para ele, a aliança de Lula com o PMDB, após o escândalo do "mensalão", ainda em 2005, foi fundamental para que

a aliança com o empresariado nacional (fosse) progressivamente se firmando. Com o tempo, não apenas as grandes empreiteiras, as grandes empresas industriais, mineradoras e de serviço aderiram ao pacto lulista, mas também - fato inédito - os setores ruralistas, que até ali continuavam a hostilizar o PT e o governo Lula. Se é fato que o boom de commodities teve grande influência nessa adesão, foi pelo menos de igual importância para isso a sua representação no governo mediante a aliança com o PMDB. Esse movimento de adesão continuou se ampliando até o governo Dilma, momento em que se alinharam ao pacto até mesmo as lideranças ruralistas tradicionais de oposição, como foi o caso da senadora Kátia Abreu, presidente da Confederação Nacional da Agricultura e Pecuária do Brasil (CNA) (Nobre, 2013, p. 119-120).

Após a fracassada política de alianças, marcada por uma forma de "corrupção de go- vernabilidade (2003-2005), o esforço de responder à crise do "mensalão" levou a mais uma inflexão conservadora do pacto lulista, acelerando o distanciamento com as bases históricas do PT. No caso do Ministério das Cidades, por exemplo, a substituição de Olívio Dutra (PT) por Márcio Fortes (PP) em 2005 gerou conflitos entre o governo e os movimentos sociais. Vários quadros, principalmente ligados ao Movimento de Reforma Urbana, decidiram entregar os seus cargos, quando não foram exonerados (Serafim, 2013). Deste modo, o pacto de classes se revela também no plano político-institucional, com a incorporação do PMDB e de partidos de direita e de centro (PP, PR, PRB...) ao governo de Lula e posteriormente de Dilma. O quadro a seguir ilustra esse fortalecimento dos partidos pragmáticos nos governos Lula e Dilma (e a diminuição da parte dos ministérios controlados pelo PT).

O PT controlava 19 dos 32 ministérios em 2003, e apenas 9 dos 31 em 2015. O PMDB, que não participava no primeiro governo Lula, entrou no governo em 2005 - após o escândalo do mensalão - recebendo 3 pastas, ganhando 5 das 35 pastas (14\%) em 2007, 6 das 37 (16\%) em 2011 e 7 das 31 (22,5\%) em 2015. Os partidos conservadores também ganharam espaço na presidência da Câmara dos Deputados (PP em 2005, PMDB em 2009-2010 e logo entre 2013 e 2016), enquanto o PMDB sempre controlou a presidência do Senado Federal entre 2003 e 2016.

Os anos de permanência de Lula, Dilma e do PT à frente do governo federal foram possíveis, pois, o projeto político não ameaçava - talvez à exceção de algumas ações do primeiro mandato de Dilma no chamado "ensaio desenvolvimentista” (Singer, 2015) - a histórica estrutura de dominação de setores conservadores e proprietários da elite econômica e política. A combinação entre política econômica neoliberal e a inclusão de amplas camadas de despossuídos possibilitou o regime de conciliação de classes que se tornou dominante no segundo mandato de Lula e até meados do pri- 
meiro mandato de Dilma, inclusive, com o virtual desaparecimento da oposição política até então sustentada no Congresso Nacional pelo PSDB e pelo DEM.

Gráfico 1 - Evolução da participação dos partidos nos governos Lula e Dilma (por número de ministérios controlados)

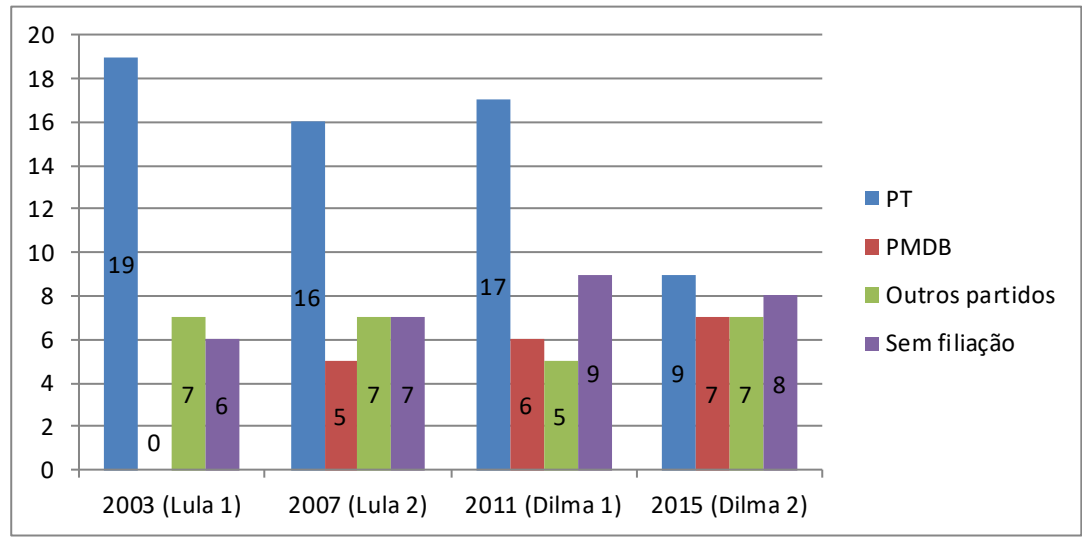

Fonte dos dados: Louault (2012)

Será possível considerar esta interpretação do lulismo como categoria analítica a nos auxiliar a compreender o lugar das instituições participativas neste contexto? Entendemos que sim e buscaremos mostrar como a lógica lulista também permeou a relação entre os governos petistas e a ação nos conselhos, conferências e outros mecanismos de participação institucional. Antes, porém, mostraremos como a literatura relacionou a incorporação dos movimentos sociais, inclusive, o movimento sindical, ao Estado no período estudado. Aqui, a literatura coloca petismo e lulismo como pólos quase integralmente opostos de ação política e de instrumentalização da participação institucional e da relação dos governos com os movimentos sociais. A seguir, buscaremos demonstrar as fragilidades desta visão e nossa compreensão sobre este ponto.

\section{PETISMO VS. LULISMO?}

O que teria se passado com o PT a partir da chegada deste partido ao governo federal, nas eleições de 2002? Como explicar que as expectativas por um governo amplamente participativo e confrontador da ordem não tenham se realizado?

A literatura tem se debruçado sobre o que configuraria uma mudança de referencial político no PT que chega ao governo federal, sob liderança de Lula. A marca principal seria a edição da Carta ao Povo Brasileiro, ainda no período eleitoral. É neste ponto que se busca diferenciar aquelas que seriam características prévias a 2002 e posteriores a 2002 na condução política do PT e, por consequência, de onde alguns autores entendem uma diferenciação de fundo entre o lulismo e o petismo.

Em um dos primeiros textos a elaborar esta visão, Baiocchi, Braathen e Teixeira (2012) caracterizam o petismo a partir do chamado “modo petista de governar", isto é, pelas ideias de inversão de prioridades, democracia participativa, luta contra a corrupção e pela ética, e respeito às diversidades que teriam caracterizado os governos municipais petistas nos anos 1990. Tal fenômeno inovador da política brasileira teria alcançado seu apogeu e, ao mesmo tempo, iniciado forte declínio com a eleição de Lula à presidência em 2002. A liderança de Lula teria também minado a democracia interna ao PT, com um pragmatismo centralizador. O "mensalão" teria sido o símbolo da impossibilidade de sobrevivência do velho petismo em um novo contexto político. O lulismo, para os autores, teria "substituído as instituições de participação política local por instituições econômicas de abrangência nacional, a saber, transferências financeiras federais, a habitação e o mercado de consumo como principais 
espaços de mudança” (Baiocchi, Braathen e Teixeira, 2012, p. 232). Portanto, o crescimento econômico, o Bolsa Família e o acesso ao crédito teriam substituído as políticas petistas na passagem do local ao nacional. Ainda, com base nas afirmações de Rennó e Cabello (2010), os autores sustentam que o lulismo teria sido incapaz de gerar uma identificação ideológica à esquerda. O lulismo seria uma espécie de rendição de um PT anteriormente participativo à lógica do presidencialismo de coalizão brasileiro e do apelo aos ganhos na economia.

Ruy Braga (2014) também argumenta sobre a mudança de estratégia do PT no governo federal, que seria incoerente com atuação anterior do partido. $\mathrm{O}$ autor recupera o texto de 2010 de Francisco de Oliveira e compara as posições críticas do autor com as posições de Singer (2009), colocando-o no debate sobre as características do lulismo. Oliveira, então, já criticava a ação dos grandes sindicatos cutistas - no interior do Estado e na gestão dos fundos de pensão das estatais - como gestores do avanço capitalista no Brasil.

Já no primeiro mandato, Lula havia sequestrado os movimentos sociais e a organização da sociedade civil. O velho argumento leninista-stalinista, de que os sindicatos não teriam função num sistema controlado pela classe operária, ressurgiu no Brasil de forma matizada. Lula nomeou como ministros do Trabalho ex-sindicalistas influentes na CUT. Outros sindicalistas estão à frente dos poderosos fundos de pensão das estatais. Os movimentos sociais praticamente desapareceram da agenda política. Mesmo o MST vê-se manietado pela forte dependência que tem em relação ao governo, que financia o assentamento das famílias no programa da reforma agrária. (Oliveira, 2010, p.25).

Nesta linha também se coloca Ricci (2010). O autor argumenta que "os movimentos sociais dos anos 80 eram declaradamente refratários em relação a toda institucionalidade pública que considerava viciada e exclu- dente” (Ricci, 2010, p. 9-10). ${ }^{5}$ Com a Constituição Federal de 1988 e a criação de "estruturas híbridas” de gestão participativa, afirma Ricci, "as lideranças de muitos movimentos sociais (principalmente urbanos), alteraram sua prática e agenda política. Passaram a assumir parte das tarefas de formulação dos gestores. Começaram a aprender os caminhos e descaminhos da administração pública, tiveram que se formar tecnicamente.” (Ricci, 2010, p. 10).

Esta literatura que separa um antes e um depois de 2002 se referencia em interpretações sobre o surgimento e desenvolvimento inicial do PT esboçadas nos anos 1990 em que o PT era visto como o "partido dos movimentos sociais" (Paoli, 1995) ou pela "lógica da diferença” (Keck, 1991) com relação aos outros partidos. O PT era visto muito mais como um elemento de articulação das demandas dos representantes dos movimentos sociais e da sociedade civil com o Estado, ao invés de um partido político engajado em disputas eleitorais.

Nossa compreensão é distinta. Entendemos que a dicotomia expressa pela visão de um PT virtuoso e posicionado no embate entre a classe trabalhadora e as classes proprietárias dos anos 1980 e 1990 e um PT lulista que teria feito o jogo da conciliação de classes nos anos 2000 é parcial, e não revela as dificuldades enfrentadas por governos locais petistas no período anterior à chegada de Lula ao poder. Há inúmeros relatos de casos em que foi necessário estabelecer - ao mesmo tempo - relações com setores do empresariado e os movimentos sociais. Mesmo as experiências de Orçamento Participativo tiveram que se abrir à participação das classes médias e do contato com o empresariado nos "Congressos da Cidade", como em Santo André (Teixeira, 2005) e Porto Alegre (Pont, 1996). Também, diversas prefeituras petistas tiveram que lidar com as grandes empreiteiras para a realização de obras viárias, de norte a sul do país. Ao mesmo tempo, a cons50 que nos parece uma visão ingênua e idealista. 
trução de governabilidade nos governos petistas foi paulatinamente deixando de se dar no confronto aberto com os partidos de centro e/ ou direita, como se observou nos casos da prefeitura de Porto Alegre com Olívio Dutra (Dias, 2002), de São Paulo com Luiza Erundina (Singer, P., 1996), de Barra Mansa-RJ (Neves, 2008), etc. Em diversos governos locais petistas a necessidade de criação de maiorias estáveis se fez presente e o método para criar tais maiorias não foi apenas aquele ligado à construção da democracia participativa ou ao contato com movimentos sociais. Deste modo, consideramos que não há oposição entre um PT "petista” pré 2002 e um PT “lulista” pós 2002. Há muito mais permanências e continuidades do que rupturas, ao contrário do que parecem defender Oliveira (2010) , Ricci (2010) Baiocchi, Braathen e Teixeira (2012) e Braga (2014).

Uma visão mais matizada sobre os movimentos sociais apareceu com Abers, Serafim e Tatagiba (2014), no campo dos estudos sobre as interações entre sociedade civil e Estado. A partir de estudos realizados no campo da política urbana, de desenvolvimento agrário e de segurança pública, as autoras descrevem a ação de militantes de movimentos sociais na "era Lula", em um contexto de "maior proximidade" entre movimentos sociais e atores estatais, que resultaram em uma ampliação das "possibilidades de combinações novas e criativas em relação aos padrões estruturais de interação" (Abers, Serafim, Tatagiba, 2014, p. 327). Para nossos objetivos, interessa salientar que as autoras remetem a existência destes novos repertórios de interação à "presença de aliados dos movimentos sociais em postos-chave no interior do Estado" (ibidem, p.327) - de maneira alternativa aos repertoire of contention (Tilly, 2008). Elas identificaram quatro tipos de repertórios de interação: a) protestos e ação direta; b) participação institucionalizada, como nos conselhos, conferências e orçamento participativo, com papel central dos atores estatais em criar e conduzir o processo de interação; c) política de proximidade, contatos diretos entre pessoas que estão no Estado com atores da sociedade civil, sobretudo, quando os militantes assumem posições no Estado; e d) ocupação de cargos na burocracia (Abers, Serafim, Tatagiba, 2014, p. 332-334).

Nogueira (2017) inspira-se fortemente na proposição das autoras para demonstrar - a partir do caso do Programa Nacional de Desenvolvimento Sustentável em Territórios Rurais (Pronat) - que a participação dos movimentos sociais do campo no Ministério do Desenvolvimento Agrário (MDA) se dá, sobretudo, pela ocupação de cargos na burocracia do MDA. A divisão do Ministério se dá por secretarias entre as organizações e movimentos no campo - Secretaria de Desenvolvimento Territorial e Secretaria de Reordenamento Agrário com a Contag, Instituto de Colonização e Reforma Agrária (Incra) com o MST e Secretaria de Agricultura Familiar pela Federação dos Trabalhadores na Agricultura Familiar (Fetraf). Esta ação é reforçada pelo domínio destes movimentos e organizações nos conselhos territoriais que estruturam o Programa. Deste modo, a ação dos movimentos sociais junto aos governos petistas é vista como estratégia de fortalecimento dos mesmos, e não de cooptação.

Deste modo, nossa percepção do lulismo se afasta de visões que realizam um julgamento do PT antes e depois de 2002 ao observar apenas o nível federal. Ao contrário, entendemos que não foi Lula o inaugurador de uma relação política que agregou ao campo petista os partidos políticos de centro e direita e que, por outro lado, agregou forças sociopolíticas ligadas ao mundo do mercado aos projetos de governos petistas. Além disso, também nos governos locais a tônica era de uma relação ao mesmo tempo fluída e tensa com os movimentos que formavam sua base social. ${ }^{6}$ Assim, se consideramos que muito do que é qualificado como práticas do lulismo já ocorrera nos go-

6 A este respeito seria oportuno o retorno a trabalhos sobre as experiências de governos locais petistas dos anos 1980 e 1990, em sua relação com movimentos sociais e com iniciativas de democracia participativa. 
vernos locais, qual sua particularidade? Como isso se vincula aos movimentos sociais e às instituições participativas? É o que desenvolveremos a seguir.

\section{O SENTIDO POLÍTICO DA PARTI- CIPAÇÃO INSTITUCIONAL SOB A ÉGIDE DO LULISMO}

Como podemos compreender as instituições participativas e o desenvolvimento limitado de uma "arquitetura nacional de participação" no contexto do lulismo? Embora não possua o monopólio da criação e defesa da participação institucional no país - afinal, conselhos de políticas públicas e conferências nacionais foram construídos em meio ao processo de redemocratização brasileira, uma obra realizada a muitas mãos - o PT se notabilizou por introduzir propostas e práticas de democracia participativa quando ocupou governos municipais e estaduais. A construção e o funcionamento da arquitetura participativa no Brasil ganhou novo fôlego no âmbito do lulismo. Propomos que o marco da aplicação do conceito de lulismo sobre as instituições participativas (IPs) se dê a partir da percepção de seus sucessos como experiência de incorporação dos movimentos sociais em processos decisórios sobre alguns setores de políticas públicas, mas sobretudo considerando seus limites em termos de inclusão, efetividade e, por fim, legitimidade como instrumento de cooperação e conflito com o governo.

A partir de 2002 ao nível federal, mas antes disso, em muitos municípios e estados, os movimentos sociais, sindicatos e grupos organizados da sociedade civil brasileira tradicionalmente perto da esquerda e do PT foram gradualmente incluídos como parte do chamado "triângulo político" no coração do lulismo (Mayaux, 2013), ao lado das elites políticas e econômicas. Como Baiocchi, Braathen e Teixeira (2012) apontam, os ganhos parciais da sociedade civil no contexto lulista incluem a participação institucional como elemento constitutivo do sistema político. Entre outros espaços, os conflitos entre os movimentos sociais, o governo e os setores conservadores da sociedade brasileira que antes eram resolvidos apenas nas ruas e na pressão política por meio de ocupações e ação direta foram levados aos processos políticos formais, ou seja, dentro das instituições de representação política e na criação, ampliação e fortalecimento das estruturas participativas formais. Isso não quer dizer que os movimentos sociais, dependendo dos setores e das relações deles com a construção do PT, não protestavam nas ruas. De fato, as instituições participativas não se substituíram aos demais repertórios de ação coletiva dos atores sociais (Abers, Serafim \& Tatagiba, 2014). Ao contrário, as IPs como interface socio estatal se tornaram um espaço a mais para fazer demandas, expressar interesses de determinados setores sociais e entrar em relação com o Estado. A partir de 2003, a realização regular e ampla de conferências de políticas públicas teria sido o ponto alto do "ritual" dos movimentos sociais de ir a Brasília, com a oportunidade de inserção institucional de novos temas advindos da sociedade civil nestes espaços. Isso se articularia ao recrutamento de líderes para cargos políticos destes movimentos, fato que - contrariamente ao que alguns observadores como Oliveira (2010) apontaram - não é caracterizado como cooptação pelas autoras.

Porém, a ambição participativa do governo federal reflete o princípio do lulismo, isto é, que a inclusão formal e o papel mais importante dos movimentos sociais na estrutura participativa

não tem subvertido a hegemonia classista tradicional que existia na sociedade. Porém, deu um papel muito mais importante aos movimentos sociais na tomada de decisões que possibilitou o envolvimento deles em ação coletiva que fortaleceu os direitos políticos deles e o processo democrático [...] sem mudar a ordem neoliberal e conservadora, nem a estrutura de representação dos interesses nos processos de tomada de decisões sobre políticas públicas (Nogueira, 2017, p.234) 
Compreendemos, portanto, que há um campo de estudos sobre participação institucional no Brasil recente que aparenta estar desconectado de uma compreensão mais ampla sobre o regime político lulista no qual os mecanismos de participação estavam ancorados e pelo qual estes mesmos mecanismos encontraram seus próprios limites.

Ora, a chegada do PT ao governo federal dá outra amplitude aos desafios da participação, para muito além do que havia sido realizado nas gestões municipais e estaduais do PT. Inovações em participação social teriam que ser redimensionadas e o mecanismo para se realizar a mobilização social do Orçamento Participativo em nível nacional, em um país continental e com políticas públicas fortemente centralizadas, foram as conferências nacionais de políticas públicas (Romão, 2015a). Ali, e não de maneira proposital, materializou-se um sistema de participação social que articulava os movimentos sociais e os gestores públicos sem que, em realidade, houvesse um processo decisório que impactasse realmente os setores - a não ser em setores mais consolidados e onde a participação pela via das conferências era algo tradicional, como na saúde (Romão, Gurza Lavalle, Zaremberg, 2017).

Não por acaso, o tema que permeou os estudos sobre as conferências e os conselhos nacionais passou a ser o da efetividade, a partir de meados do segundo mandato de Lula (Pires, 2011). Embora mobilizasse milhões de pessoas em processos participativos ocorridos nos três níveis da federação e em dezenas de setores de políticas públicas - investindo-se parcela relevante do orçamento público - não estava claro o quanto as conferências (e também os conselhos e outros mecanismos) de fato influenciavam os processos decisórios nas secretarias e ministérios.

Enquanto as conferências nacionais permaneciam ocorrendo, o Congresso Nacional pouco se afetava por elas. ${ }^{7}$ As decisões polí-

7 Embora existam interpretações alternativas sobre este tema. Ver Pogrebinschi e Santos (2010). ticas de peso - como as reformas da previdência, os grandes programas de transferência de renda e habitacionais, as decisões em infraestrutura e as matérias em política econômica - permaneciam se dando ao largo dos espaços participativos. Por outro lado, as conferências - e, em menor grau, os conselhos - destravaram um conjunto expressivo de temas para o debate público, sobretudo quanto aos direitos humanos de toda ordem e, nelas, permaneceu a vocação participativa e mobilizadora do PT, inclusive com a inclusão de novos temas de políticas públicas na agenda política como políticas para as mulheres, juventude, igualdade racial e outros. Mais do que se limitar à esfera nacional, as cerca de 100 conferências ocorridas nos governos Lula e Dilma mobilizaram milhões de membros das comunidades de políticas (Kingdon, 1995) que atenderam ao chamado da elaboração conjunta de propostas para a ação governamental.

Assim, as conferências nacionais podem ser apontadas como expressões dos avanços e dos limites da participação institucional sob o lulismo. Tais limites ficaram mais claros quando, além da base de apoio tradicional do petismo, setores mais conservadores ou mais radicalizados das comunidades de políticas ambos anti-lulistas - se mostraram dispostos a participar das conferências. Três exemplos ilustram isso:

1) 1a Conferência Nacional de Comunicação (2009): os setores tradicionalmente ligados ao petismo e militantes pela causa da democratização da comunicação se encontraram com grupos de mídia para esta conferência, que terminou com a retirada dos membros dos grupos empresariais. Ao final, o ministério das Comunicações tomou a decisão política de não avançar em um novo marco legal para o setor.

2) 1a Conferência Nacional de Segurança Pública - Conseg (2009): buscava-se também o estabelecimento de uma coalizão para colocar em prática uma reforma do sistema de segurança pública no país. De pronto, a Conseg 
não conseguiu agregar, em sua organização, os movimentos ligados aos direitos humanos, que não concordavam em se sentar frente a frente com alguns dos algozes de seus familiares - os policiais militares. A Conferência ocorreu por um sistema de priorização que possibilitava a existência de pontos contraditórios como, por exemplo, a desmilitarização das polícias e a manutenção das polícias militarizadas. Nenhum ponto do esboço da reforma avançou.

3) 4a Conferência Nacional de Meio Ambiente (2013): com o boicote de parte dos grupos e movimentos ambientalistas - que se ausentaram dos debates conferenciais pela própria saída de Marina Silva do governo e, sobretudo, pelo avanço das grandes obras de infraestrutura e energia na Amazônia -, a Conferência teve seu foco sobre a política nacional de resíduos sólidos. Neste caso, parte de uma base, se não orgânica, ao menos simpática aos governos petistas no âmbito do ambientalismo, se desprende do governo e este passa a dar lugar para uma base movimentalista mais recente, formada pelos catadores de resíduos sólidos.

Deste modo, as instituições participativas se conformaram ao princípio lulista em que, por um lado, dava-se voz aos grupos e movimentos sociais há muito excluídos de participação relevante no cenário político nacional sem que, por outro lado, atribuísse a elas poder real de decisão: "o lulismo não inverteu a estrutura de dominação no Brasil, e nem foi só um pacto social pela estabilidade e governabilidade, mas permitiu que muitas variáveis como classes, ação coletiva e governabilidade interagissem de várias maneiras, seja do conflito até cooperação como resposta a uma variedade de pressões” (Nogueira 2017, p. 236)

Com base em trabalhos de Pires e Vaz (2012), Almeida (2017) lembra que

experiências coletivizadas e mais institucionalizadas, como conselhos e conferências, apresentaram maior vínculo relativo aos programas da área de proteção e promoção social, enquanto experiências mais pontuais de participação ou individualizantes, como audiências, ouvidorias e reuniões com grupos de interesse, estão mais presentes nas temáticas que envolvem infraestrutura e desenvolvimento econômico. A baixa adesão à participação em áreas estratégicas do governo que lidam com o planejamento e o orçamento federal são obstáculos para pensar a articulação com o sistema político. (Almeida, 2017, p. 659-660).

O pacto lulista permite a inclusão dos movimentos sociais nos debates sobre as políticas públicas sem ameaçar o capital e os setores conservadores. No pacto, as instituições participativas - mais além até do que a institucionalização de movimentos sociais em determinados ministérios e secretarias - atuam para incluir as bases dos movimentos, articulando-os àqueles que se burocratizaram no Estado, e promovendo políticas voltadas aos seus objetivos e necessidades, desde que não incomodem o capital. ${ }^{8}$ Porém, por contar com o compromisso com as classes conservadoras e por não ameaçar a ordem política da democracia representativa e dos processos de tomada de decisões para a sua própria existência institucional, as instituições participativas desenvolvidas no marco do lulismo também contêm tensões inerentes entre os participantes, padrões de efetividade política fraca e, consequentemente, de carência de legitimidade face às instituições representativas. Portanto, pode-se argumentar que como parte do regime lulista, as instituições participativas brasileiras apresentam limites para se desenvolver num sistema de participação coerente, coesivo e organizado em nível nacional. Isto fica mais explícito ao analisarmos a tentativa frustrada de institucionalização dessa arquitetura participativa sob o decreto presidencial que criaria a Política Nacional de Participação Social (PNPS), publicado em 2014. É o que faremos a seguir.

8 As conferências tinham o condão de até mesmo incluir aquelas facções de movimentos que não apresentaram força política para estarem presentes no Estado. 


\section{JUNHO DE 2013 E A POLÍTICA NA- CIONAL DE PARTICIPAÇÃO SOCIAL: o esgotamento do lulismo?}

As manifestações de junho de 2013 destacaram as fissuras do lulismo e as contradições nas quais o modelo lulista de governar se enraizou. Mais ainda, o movimento se configura, para autores como Mayaux (2013), como um sinal do "esgotamento do lulismo". A evolução das políticas participativas e sua relação com o "triângulo político" em seu seio e em torno deles permite pensar a continuidade do lulismo como regime político sob o governo de Dilma Rousseff, e de pensar com perspectiva teórica alguns elementos do seu chamado esgotamento, da crise política que marcou o seu segundo mandato e da destituição da Presidenta.

As análises sobre as causas do movimento de junho 2013 e sobre as características dos manifestantes (Singer, 2013; Bringel, Pleyers, 2015) apontam algumas explicações - menos exploradas na literatura - que se encontram no descontentamento de setores das classes baixas e de parte dos setores sociais que ficaram de fora da incorporação dos movimentos sociais tradicionais no âmbito do lulismo - inclusive do âmbito das instituições participativas (Avritzer, 2016). Muito da falta de efetividade das instituições participativas se encontrou com setores entre os quais não só havia rejeição aos conselhos e conferências, mas que absolutamente desconheciam a existência destes espaços de participação. Muitos setores, como os indígenas, os ambientalistas, as mulheres, grupos ligados à diversidade sexual e racial, não se sentiam incluídos pelas possibilidades abertas de participação nos marcos lulistas e recusavam a "blindagem" do sistema político (Nobre, 2013).

Não é possível se falar em uma "resposta” de Dilma Rousseff às manifestações de junho de 2013 com a proposição do Sistema e da Política Nacional de Participação Social
(PNPS). A iniciativa estava sendo gestada desde 2012 na Secretaria Geral da Presidência da República como uma proposta de pensar a participação como "método de governo" e com a construção de diretrizes e orientações para a implementação da participação institucional nas unidades subnacionais. No entanto, assim como o movimento de junho de 2013 mostrou as dificuldades do lulismo em incorporar novos setores sociais ao pacto político que funcionara bem no período anterior, a PNPS - mesmo tímida e apenas ordenadora de instâncias de participação social já existentes no governo federal - foi um dos instrumentos do jogo político da oposição à reeleição de Dilma e demonstração cabal da fraqueza da coalizão de seu governo.

O decreto presidencial n. 8.243, de 23 de maio de 2014 foi severamente criticado por todos os partidos políticos no Congresso Nacional, à exceção do PT e do PCdoB. Acusou-se Dilma e seu governo de usurpar as prerrogativas do Congresso Nacional, uma vez que o decreto dava margem à interpretação de que toda a formulação, execução, monitoramento e avaliação dos programas federais deveriam responder aos objetivos e diretrizes da PNPS. Além disso, a forma da propositura - um decreto e não um projeto de lei a ser levado à consideração do Legislativo - foi também bastante criticada (Romão, 2015b; Almeida, 2017).

Podemos compreender essas críticas, ao menos em parte, como uma reação dos setores conservadores da oposição política face a uma ameaça crescente à ordem política construída no pacto lulista. De fato, a PNPS, apesar de não reinventar as IPs e de apenas institucionalizar as práticas já existentes, era uma política que permitia cristalizar o papel dos movimentos sociais no triângulo político do lulismo por meio do reconhecimento e do fortalecimento de um papel potencialmente mais proeminente deles nos processos de tomada de decisóes sobre políticas públicas em todos os setores de políticas, inclusive os de determinação mais conservadora. 
Conseqüentemente, pode-se argumentar que a tentativa da Dilma Rousseff de consolidar os vínculos com os movimentos sociais depois das manifestações de 2013 com uma maior institucionalização da dimensão participativa no regime político constitui uma ruptura com o pacto de governabilidade do lulismo ${ }^{9}$.

\section{CONSIDERAÇÕES FINAIS}

Este artigo buscou explorar as características, limites e contradições do lulismo à luz das políticas de participação institucional no Brasil entre 2003 e 2016. Primeiro, discutimos o conceito de lulismo a partir da definição elaborada por André Singer (2009). Optamos por analisar o lulismo como pacto de conciliação política entre vários setores da sociedade e não apenas como tradução eleitoral desse pacto (o chamado realinhamento eleitoral de 2003-2006).

Em seguida, retomamos o debate encontrado na literatura sobre a articulação entre petismo e lulismo, no que diz respeito à relação entre os governos, os movimentos sociais e a participação institucional. Essa discussão teórica serviu de base para analisarmos o papel paradoxal das instituições participativas na consolidação do lulismo. Por um lado, criaram-se espaços de ampla mobilização dos movimentos sociais e da sociedade civil que clamava por mudanças. Por outro lado, os limites das IPs como espaço de efetivo poder explicitam também os limites institucionais e políticos do lulismo para a construção das condições para o aprofundamento da democracia no Brasil a partir da iniciativa do governo federal. Finalmente, esboçamos uma reflexão sobre as evoluções dessa articulação entre lulismo e IPs durante o governo de Dilma Rouseff.

Consideramos as manifestações de junho

9 Podemos ver outros exemplos desse distanciamento de Dilma Rousseff com o modo lulista de governar no que diz respeito às relações com as bases aliadas. Entre julho e agosto de 2013, Dilma Rousseff tentou impor o tema da reforma política na agenda política (propondo um plebiscito sobre a questão), mas teve que recuar sob a pressão do Congresso. de 2013 como o sintoma da fragilidade das políticas participativas, como sinal do esgotamento do lulismo e como fator de reavalição do pacto de governo. Há, contudo, visões alternativas sobre as IPs e seu papel nos governos Lula e Dilma. Instituições como os conselhos e as conferências nacionais até podem ser utilizados como espaços de resistência por alguns atores sociais, mesmo no âmbito do lulismo, entendido como concessão a forças políticas conservadoras e ao presidencialismo de coalizão. Mas mesmo assim, as IPs desenvolvidas no marco do lulismo foram marcadas por tensões inerentes entre os participantes e dentro dos próprios movimentos, por padrões de efetividade política baixa em termos de políticas públicas e por um alto nível de fragilidade institucional.

Recebido para publicação em 22 de agosto de 2019 Aceito em 29 de março de 2020

\section{REFERÊNCIAS}

ABERS, R.;SERAFIM, L.;TATAGIBA, L. Repertórios de interação estado-sociedade em um estado heterogêneo: a experiência na Era Lula. Dados, Rio de Janeiro, 57 (2), p. 325-357, 2014.

ALMEIDA, D. R. Os desafios da efetividade e o estatuto jurídico da participação: a Política Nacional de Participação Social. Sociedade e Estado, Brasília, 32 (3), p. 649-680, 2017.

AMARAL, O.; POWER, T. The PT at 35: Revisiting Scholarly Interpretations of the Brazilian Workers' Party. Journal of Latin American Studies, 48 (1), p. 147-171, 2016.

AVRITZER, L. Impasses da democracia no Brasil. Rio de Janeiro: Civilização Brasileira, 2016.

BAIOCCHI, Gianpaolo; BRAATHEN, Einar; TEIXEIRA, Ana Claudia. Transformation institutionalized? Making sense of participatory democracy in the Lula Era. In: STOKKE, Kristian; TORNQUIST, Olle (eds). Democratization in the Global South: the importance of transformative politics. United Kingdon: Palgrave Macmillan, 2013.

BEZERRA, C. Os sentidos da participação para o Partido dos Trabalhadores (1980-2016). Revista brasileira de ciências sociais, v. 34, n. 100, epub setembro, 2019. 
BRAGA, Ruy. The Lula Moment: constraints in the current peripheral development model. In: FAKIER, Khayaa; ELLEN, Ehmke. Socio-economic Insecurity in Emerging Economies: building new spaces. London, New York: Routledge, 2014.

BRINGEL, B.; PLEYERS, G. Les mobilisations de 2013 au Brésil : vers une reconfiguration de la contestation. Brésil(s). Sciences humaines et sociales, 7, p. 7-18, 2015.

DIAS, M. R. Sob o signo da vontade popular: o Orçamento Participativo e o dilema da Câmara Municipal de Porto Alegre. Belo Horizonte: UFMG; Rio de Janeiro: IUPERJ, 2002.

GURZA LAVAlLE, A., BARONE, S.L. Conselhos, Associações e Desigualdade. In: ARRETCHE, M. (org.). Trajetórias das desigualdades. Como o Brasil mudou nos últimos cinquenta anos, São Paulo: UNESP/CEM, $1^{\mathrm{a}}$ ed., 2015. p. 51-76.

KINGDON, J. Agendas, alternatives and public policies. New York: Harper Collins College Publishers, 1995.

KECK, M. PT: A lógica da diferença. O Partido dos Trabalhadores na construção da democracia brasileira. São Paulo: Ática, 1991.

LOUAULT, F. Un renouvellement brésilien en trompe-l'œil ? In : DABENE, O. (dir.). La Gauche en Amérique latine, 1998-2012, Paris,Presses de Sciences Po, 2012, p. 35-74.

MAYAUX, P-L. Lépuisement du lulisme ou la fin d'un triangle politique: les manifestations brésiliennes de juin 2013. In Observatoire Politique de l'Amérique latine et des Caraïbes - Working paper, Paris: CERI-SciencesPo, 2013.

MONTAMBEAULT, F. Uma Constituição cidadã? Sucessos e limites da institucionalização de um sistema de participação cidadã no Brasil ㄱ democrático. Estudos Ibero-Americanos, v. 44, n. 2, p. 261-272, 2018.

MONTAMBEAULT, F. BALÁN, M.; OXHORN, P. Widening and Deepening Citizenship from the Left: A Relational and Issue Based Approach. In: BALÁN, M.; MONTAMBEAULT, F. (orgs.) Legacies of the Left in Latin America: The Promise of Inclusive Citizenship, Notre Dame University Press, 2019.

NEVES, A. Cultura política e democracia participativa: um estudo sobre o orçamento participativo. Rio de Janeiro: Gramma, Faperj, 2008.

NOBRE, M. Imobilismo em movimento: da abertura democrática ao governo Dilma. São Paulo: Companhia das Letras, 2013.

NOGUEIRA, A. S. Lulism and the Institutionalization of Social Movements in Brazil: Strenghtening
Democratic Inclusion and Perpetuating Hegemony. Tempo Social, São Paulo, 29 (3), p. 229-260, 2017.

OLIVEIRA, F. Hegemonia às avessas. In: OLIVEIRA, F.; BRAGA, R.; RIZEK, C. (orgs.). Hegemonia às avessas: economia, política e cultura na era da servidão financeira. São Paulo: Boitempo, 2010.

PAOLI, M. C. Movimentos sociais no Brasil: em busca de um estatuto político. In: HELLMANN, M. (org.). Movimentos sociais e democracia no Brasil: "Sem a gente não tem jeito". São Paulo: Marco Zero, Ildes-FES, Labor, 1995.

PIRES, R. (org.). Efetividade das instituições participativas no Brasil: estratégias de avaliação. Brasília: IPEA, 2011.

.VAZ, A. Participação social como método de governo? Um mapeamento das "interfaces sociestatais" nos programas federais. Brasília: Ipea. (Texto para Discussão, n. 1707), 2012.

POGREBINSCHI, T.; SANTOS, F. Participação como representação: o impacto das conferências nacionais de políticas públicas no Congresso Nacional. Dados, v. 54, n. 3, p. 259-305, 2011.

PONT, R. A capital da democracia. Teoria e Debate, n. 32, julho, 1996.

RENNÓ, Lúcio; CABELLO, Andrea. 'As bases do lulismo: a volta do personalismo, realinhamento ideológico ou não alinhamento?'. Revista Brasileira de Ciências Sociais, v. 25, n. 74, p. 39-60, 2010.

RICCI. R. Lulismo: da era dos movimentos sociais à ascensão da nova classe média brasileira. Rio de Janeiro, Contraponto Editora, 2010.

ROMÃO, W. M. Políticas públicas y democracia participativa: avances y límites de las conferencias nacionales en Brasil. In: MINNAERT, A.; ENDARA, G. (orgs.). Democracia participativa e izquierdas: logros, contradicciones y desafíos. Quito, Ecuador: Fridrich Ebert Stiftung, 2015 (2015a).

. Reflexões sobre as dificuldades da implementação da participação institucional no Brasil. Idéias - Revista do IFCH-UNICAMP, v. 6, n. 2, p. 35-58, jul/dez, 2015 (2015b).

ROMÃO, W.; GURZA LAVALLE, A.; ZAREMBERG, G. Political intermediation and public policy in Brazil: councils and conferences in the policy spheres of health and women's rights. In: ZAREMBERG, G.; GUARNEROS-MEZA, V.; GURZA LAVALLE, A.(orgs.). Intermediation and representation in Latin America: actors and roles beyond elections. Palgrave Macmillan, 2017. p. 31-52.

SAMUELS, D. As bases do petismo. Opinião publica, v. 10, n. 2, p. 221-241, 2004. 
Wagner Romão, Françoise Montambeault, Frédéric Louault

SANCHEZ, F. Orçamento Participativo, teoria e prática. São Paulo : Cortez, 2002.

SECCO, L. História do PT (1978-2010). Cotia: Ateliê, 2011.

SINGER, P. Um Governo de Esquerda para Todos. Brasiliense, 1996.

SINGER, A. Esquerda e direita no eleitorado brasileiro: a identificação ideológica nas disputas presidenciais de 1989 e 1994. São Paulo: Edusp, 2000 .

.Raízes sociais e ideológicas do lulismo. Novos Estudos - CEBRAP, 85, p. 83-102, 2009.

.Os sentidos do lulismo: reforma gradual e pacto conservador. São Paulo: Companhia das Letras, 2012.

."Brasil, Classes e ideologias cruzadas." Novos Estudos - CEBRAP, 97, p. 23-40, 2013.

"Cutucando onças com varas curtas". Novos Estudos - CEBRAP, 102, p. 39-67, 2015.

TEIXEIRA, M. A. C. Análise crítica do processo de elaboração e implantação do Plano Diretor Participativo de Santo André (SP). Cadernos Gestão Pública e Cidadania, V. 10,, n. 46 - Jan/Abr., p. 6480, 2005.

Para além do voto: uma narrativa sobre a democracia participativa no Brasil (19752010). Tese de Doutorado. Programa de PósGraduação em Ciências Sociais. IFCH-Unicamp, 2014.

TRANJAN, R. Participatory Democracy in Brazil: socioeconomic and political origins. Notre Dame: Notre Dame Press, 2016.

TILLY, C. Contentious Performances. Cambridge, Cambridge University Press, 2008.

ZUCCO Jr., Cesar. The President's "New" Constituency: Lula and the Pragmatic Vote in Brazil's 2006 Presidential Elections. Journal of Latin American Studies, n. 40, p. 29-49; 2008.

. When Payouts Pay Off: Conditional Cash Transfers and Voting Behavior in Brazil, 2002-2010. American Journal of Political Science, v. 57, n. 4, p. 810-822, 2013. 


\section{PARTICIPATORY INSTITUTIONS UNDER LULISMO}

\author{
Wagner Romão \\ Françoise Montambeault \\ Frédéric Louault
}

The Lulismo thesis (Singer, 2012) is based on the idea that both Lula and Dilma's electoral bases moved from the middle class to voters with an median average income of up to two minimum salaries. However, lulismo is more than that: it suggests that Lulismo allows for na improvement of living conditions of the poor without harming conservative sectors. The concept of weak reformism best captures this phenomenon, according to Singer. Our paper proposes an analysis of the Lula-Dilma period's participatory policies from this theoretical standpoint. A central element of the PT's participatory democracy project for Brazil, the so-called participatory institutions (PIs), mobilized new progressive sociopolitical actors coming from their traditional support bases. However, PIs remained quite limited in terms of their political effectiveness and lacked legitimacy against representative democratic institutions, which is coherent with lulismo.

KEYwORDs: Intitucional resilience, Institutional participation, National councils, Health, Women's rights.

\section{LES INSTITUTIONS PARTICIPATIVES SOUS L'ÉGIDE DU LULISME}

\author{
Wagner Romão \\ Françoise Montambeault \\ Frédéric Louault
}

La thèse du « lulisme » (Singer, 2012) repose sur l'idée que les bases électorales de Lula et de Dilma Rousseff sont passées de la classe moyenne à des électeurs dont le revenu moyen médian est inférieur ou égal à deux salaires minimums. Cependant, le lulisme est plus que cela : en effet, il permet une amélioration des conditions de vie des populations pauvres sans nuire aux secteurs conservateurs. Selon Singer, c'est le concept de réformisme faible qui rend le mieux compte de ce phénomène. Notre article propose une analyse des politiques participatives de la période Lula-Dilma à partir de ce point de vue théorique. Elément fondamental du projet politique de démocratie participative porté par le Parti des travailleurs au Brésil, les institutions participatives (IP) ont mobilisé des acteurs sociopolitiques faisant partie de sa base d'appui traditionnelle. Cependant, en raison des caractéristiques mêmes du lulisme, leur efficacité demeure limitée du point de vue politique et ces IP font état d'un déficit de légitimité par rapport aux institutions de démocratie représentative.

MotS CLÉS: Institutions participatives, Lulisme, Pétisme, Mouvements sociaux, Gouvernement.

Wagner Romão - Doutor em Sociologia pela USP. Professor do Departamento de Ciência Política da Unicamp. Coordenador do Núcleo de Pesquisa em Participação, Movimentos Sociais e Ação Coletiva (NEPAC/Unicamp). Desenvolve pesquisas sobre participação, democracia e políticas públicas. Suas publicações mais recentes são "Participation", The Routledge Handbook to the Political Economy and Governance of the Americas, editado por Olaf Kaltmeier et. al. (2020); e "Democratic innovations in Municipalities" (com Brian Wampler), The Routledge Handbook of Brazilian Politics, editado por Barry Ames (2019).

Françoise Montambeault - Doutora em ciências politicas da Universidade McGill (Canada), Professora do Departamento de ciências politicas da Université de Montréal (Canada), titular da Cátedra de Pesquisa do Canada em Participação e Cidadania(s), Diretora da Equipe de pesquisa interuniversitária sobre inclusão e governança na América Latina (ERIGAL), desenvolvendo pesquisas na área de participação social, cidadania e democracia participativa. Suas mais recentes publicações são: "It was once a radical proposal: Theories of gradual institutional change in Brazilian participatory budgeting”, Latin American Politics and Society (2019, 61:1, p. 29-53); Legacies of the left in Latin America: The promises of inclusive citizenship (co-editora com Manuel Balán), Notre Dame University Press, 2019; The politics of participatory democracy in Latin America, Stanford University Press, 2015.

Frédéric Louault - Doutor em ciência política pela Sciences Po Paris (França), Professor do Departamento de ciência política da Université Libre de Bruxelles (Bélgica), diretor-adjunto do Centro de Estudos da Vida Política (CEVIPOL) et co-diretor do Centro Interdisciplinario de Estudos das Américas (AmericaS). Ele foi vice-decano da Faculdade de Filosofia e Ciências Sociais da ULB em cargo das Relações internacionais (2016-2019). Suas pesquisas se focalizam nas areas da sociologia política e da política comparada (participação política, eleições, carreiras políticas na América latina). 